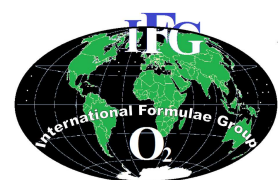

Available online at http://ajol.info/index.php/ijbes

Int. J. Biol. Chem. Sci. 8(3): 871-881, June 2014

ISSN 1997-342X (Online), ISSN 1991-8631 (Print)

Original Paper

http://indexmedicus.afro.who.int

\title{
The effect of vitamin supplementation on the toxic effects of dichlorvos on the microanatomy of rat hippocampal formation
}

\author{
Olatunde OWOEYE ${ }^{1^{*}}$, Fabian V. EDEM ${ }^{2}$, Bukola S. AKINYOOLA ${ }^{2}$, \\ Effiong E. AKANG ${ }^{3}$ and Ganiyu O. ARINOLA ${ }^{2}$
}

\author{
${ }^{I}$ Departments of Anatomy, College of Medicine, University of Ibadan, Ibadan, Nigeria. \\ ${ }^{2}$ Departments of Chemical Pathology, College of Medicine, University of Ibadan, Ibadan, Nigeria. \\ ${ }^{3}$ Departments of Histopathology, College of Medicine, University of Ibadan, Ibadan, Nigeria. \\ "Corresponding author; E-mail: oowoeye2001@yahoo.com,o.owoeye@mail.ui.edu.ng; \\ Phone: +2348033239973; Fax: +234-2-8103043.
}

\begin{abstract}
Dichlorvos (DDVP) is a widely used pesticide that is toxic to animals and humans but study of its effect on the microanatomy of the brain is scanty. This study was designed to investigate the ameliorating effect of vitamin supplementation on DDVP-induced neurotoxicity in the hippocampus of Wistar rats. 25 male Wistar rats were separated into unexposed group and those exposed to DDVP $(1000 \mathrm{mg} / \mathrm{L})$ through inhalation either without, or with vitamin $\mathrm{E}$, vitamin $\mathrm{C}$ or red palm oil supplementation. Treatment lasted for 14 days after which rats were sacrificed by ketamine anaesthesia. Hippocampal biopsies were processed into paraffin blocks and H\&E stained sections were evaluated by light microscopy. DDVP administration elicited toxicity in the dentate gyrus, cornuammonis 1 (CA1) and cornuammonis 3 (CA3) regions. There was pyknosis and alteration of the microanatomy of dentate granule cells and pyramidal cells of CA1 and CA3. DDVP-induced toxicity was mitigated by vitamins $\mathrm{E}, \mathrm{C}$ and red palm oil in the dentate gyrus, but partially in CA1 and CA3. Inhalational DDVP induces toxicity in the hippocampus of rats and this could affect memory. Toxicity of DDVP is partially ameliorated by vitamins E, C and red palm oil.

(C) 2014 International Formulae Group. All rights reserved.
\end{abstract}

Keywords: Dichlorvos, dentate gyrus, cornuammonis, hippocampus, red palm oil.

\section{INTRODUCTION}

Memory is an important component of cognition and it must first be encoded by the hippocampal formation before the memory trace is transferred to other parts of the brain for short and long-term storage (Tranel, 1995; Hendelman, 2000). The hippocampus is a brain area that is crucial for the acquisition of new memories, and is intimately involved in learning and spatial cognition (Somogyi,
2010; Vivar and van Praag, 2013). Three hippocampal subfields: dentate gyrus (DG), area CA3 and area CA1 (Kesner, 2007) each have specific cell types and plasticity contributing to learning and memory processes (Nakazawa et al., 2004). Neural information is sequentially processed from the entorhinal cortex (EC) to DG, CA3, CA1 and subiculum, to be ultimately stored in EC, forming the intrinsic hippocampal circuit 
(Amaral and Witter, 1989). Damage to any of these hippocampal structures will affect encoding of memory which will adversely affect the quality of life.

According to the World Health Organization's estimate, 3 million cases of pesticide poisoning occur every year, resulting in more than 250,000 deaths (Binukumar and Gill, 2010). Chronic exposure to pesticides could result in tissue accumulation and cause tissue injury. Dichlorvos DDVP (O-Odimethyl-O-2, 2-dichloro-vinyl phosphate) (USEPA, 2007), is an organophosphorous compound largely used to control ectoparasites in livestock and humans (Luty et al., 1998; Sharma and Singh, 2010). Organophosphorus compounds are primarily recognized to be neurotoxic in mammals as they inhibit the activity of acetylcholinestrase (AChE), an enzyme that decomposes acetylcholine (Hazarika et al., 2003). The inhibition of AChE results in an accumulation of excessive amounts of acetylcholine in synaptic clefts and muscular motor plates, thereby producing both nicotinic and muscarinic signs and symptoms of endogenous poisoning and intoxication in the peripheral and central nervous systems (Akinyoola et al., 2012). In Nigeria, a popular pesticide traded under the names such as "Ota piapia" or "Nuvan" has been reported to contain DDVP as the preponderant active pesticide ingredient (Musa et al., (2010). DDVP toxicity has been reported in reproductive system (Joshi et al., 2003), pancreas (Hagar et al., 2002), kidney and spleen (Verma and Srivastva, 2003), immune system (Neishabouri et al., 2004), liver and lungs (Owoeye et al., 2012); on haematological indices (Edem et al., 2012) and nervous tissue (Luty et al., 1998; Sharma and Singh, 2012). Studies support a role for reactive oxygen species (ROS) in the mechanism of DDVP toxicity (Sharma and Singh, 2012) and excessive generation of ROS causes irreversible impairment of DNA and damage to membrane lipids during the production of malondialdehyde (Arinola et al., 2011). Pesticides are believed to damage the lipoidal matrix in cells, generating reactive oxygen species (ROS) and promoting oxidative stress. Dueto continuous exposure of pesticides, the level of these antioxidants decreases thus leading to accelerated cell death (Sharma and Singh, 2012).

Exogenous antioxidants capable of neutralizing the effects of ROS include ascorbic acid (vitamin C, VTC), alphatocopherol (vitamin E, VTE) and red palm oil (RPO) among others. VTC isan electron donor, aproperty that accounts for all its known functions including its being a potent water-soluble antioxidant in humans, an effect that has been demonstrated in many experiments (Padayatty et al., 2003). VTE is an intracellular compound associated with lipid-rich biological membranes including those of mitochondria and endoplasmic reticulum; it is lipophilic making it a major free radical chain terminator (Singh, 2002). $\mathrm{RPO}$ is an edible vegetable oil derived from the mesocarp of the fruit of the African oil palm Elaeisguineensis. It is naturally reddish in colour because of a high content of carotenes, such as alpha-carotene, betacarotene (contains vitamin A), lycopene, and at least 10 other carotenes, along with tocopherols and tocotrienols, phytosterols, and glycolipids. RPO is thus rich in both vitamin $\mathrm{E}$ and A (Bonnie and Choo, 2000).

In previous studies of the morphological changes in nervous tissue, DDVP was administered orally or dermally (Luty et al., 1998; Desi and Nagymajtenyi, 1998). It is important to evaluate the effects via inhalation. This is so because the general population is more likely to be exposed to pesticides through inhalation of contaminated indoor air during and/or immediately after application of pesticides like DDVP as insecticides. DDVP generates reactive oxygen species which damage membrane lipids and since the brain is rich in lipids, it is hypothesised that inhaled DDVP may have impact on the brain. The objective of this research was to investigate the possible effect of inhalational DDVP on the microscopic structure of the hippocampus of rats and so test the hypothesis that antioxidant-containing vitamins could protect the neurons from 
DDVP-induced toxicity. This should assist us to answer the research question of whether vitamin supplementation can modulate the histological alteration elicited by inhalational DDVP-induced toxicity in brain of Wistar rats.

\section{MATERIALS AND METHODS \\ Experimental animals and materials}

This study was carried out using 25 ten weeks old Wistar male rats $(75.05 \pm 5.55 \mathrm{~g})$ obtained from the Animal Holding facilities of Anatomy Department, University of Ibadan, Nigeria. They were acclimatized to laboratory room conditions (12 hours dark - light period) for 2 weeks before the onset of treatment. The rats were fed during the acclimatization period with rat chow from Ladokun Feeds, Ibadan, and water ad libitum. Vitamins $\mathrm{E}$ and $\mathrm{C}$ were purchased from Dana Pharmacy, Ibadan, Nigeria, while RPO was purchased from Bodija market, Ibadan. DDVP was purchased from Farmers Shopping Plaza, Ogunpa, Ibadan, Nigeria. The experimental protocols were carried out according to acceptable guidelines on the ethical use of animals in research (Public Health Service, 1996).

\section{Research design}

After the period of acclimatization, the 25 rats were randomized into 5 equal groups as follows using a modification of the method of Edem et al. (2012). Group I: control (unexposed); Group II: exposure to DDVP alone for 4 weeks; Group III: exposure to DDVP for 4 weeks plus vitamin E $(1.25 \mathrm{~g} / \mathrm{kg}$ feed per day); Group IV: exposure to DDVP for 4 weeks plus vitamin $\mathrm{C}(106 \mathrm{mg} / \mathrm{kg}$ body weight per oram per day); Group $\mathrm{V}$ : exposure to DDVP for 4 weeks plus RPO ( $2 \mathrm{ml} / 25 \mathrm{~g}$ feed per day). The dosage of vitamin $\mathrm{E}$ was based on the method of Murthy et al. (1992), while that of vitamin $\mathrm{C}$ was according to the method of Ambali et al. (2011). DDVP (1000 $\mathrm{mg} / \mathrm{L}$ ) was prepared freshly daily in a dilution of $1: 1$ as recommended by the manufacturer (Hubei Samonda Co. Ltd, China), i.e. $50 \mathrm{~mL}$ of DDVP was mixed with $50 \mathrm{~mL}$ of clean water. The groups were separated in different cages. To simulate a poorly ventilated compartment, rats were placed in Perspex cages $(35.5 \mathrm{~cm} \times 27.5 \mathrm{~cm} \times 19 \mathrm{~cm})$, the DDVP preparation was placed beside the cage and each cage covered with a cardboard carton with only one of the upper two lids partially opened. Rat exposure to DDVP in all 5 groups lasted 4 hours daily by this inhalational method after which the DDVP solution container and the carton were removed.

\section{Sample collection and histological preparation}

At completion of exposure, the animals were anaesthetized with Ketamine $(10 \mathrm{mg} / \mathrm{kg}$ intraperitoneally). Thereafter, the brain of each animal was removed and fixed in $10 \%$ formalin for 7 days. The brains were then sectioned coronally and biopsies were obtained from the hippocampal formation at the level of the lateral geniculate body. These biopsies were subsequently processed by dehydration with increasing grades of ethanol (70, 80, 90, 95 and 100\%). Dehydration was then followed by clearing the samples in 2 changes of xylene followed by impregnation with 2 changes of molten paraffin wax, then embedded and blocked out. Paraffin sections $(5-6 \mu \mathrm{m})$ thick transverse sections of the hippocampal formation were cut using a rotary microtome (Leica RM2125RTS, Germany), and then mounted on glass slides. The slides were stained with haematoxylin and eosin (H\&E) according to the method of Bancroft and Gamble (2008).

\section{Histology}

Stained sections were examined with the light microscope (Olympus CH Japan) for histopathological studies. Special attention was paid to the dentate gyrus, CA1 and CA3 regions. Photomicrographs of these 3 regions were taken from each animal with a Sony DSC-W 30 Cyber-shot (Japan) camera at $\mathrm{x}$ 240 magnification. A scale bar was inserted in the photomicrograph using Image $\mathbf{J}$ (Schneider et al., 2012). 


\section{RESULTS}

\section{General}

Our observations showed that the neurons of control animals in the DG, CA 1, and CA 3 parts of the hippocampal formation exhibited large soma with copious cytoplasm. The nuclei of the neurons are large, ovoid or round, chromatin was dispersed and the nucleoli were conspicuous and prominent as shown in Figures 2A, 4A, and 6A.

\section{Histopathology of DG}

The DG of rats exposed to DDVP showed scattered pyknotic neurons, reduced cellularity as well as shrunken size as shown in Figure 2B. The brain of rats that received supplementation of VTE, VTC and RPO showed fairly good structure as shown by their neurons comparing well with those of control rats as displayed in Figures 3C, 3D, and $3 \mathrm{E}$.

\section{Histopathology of CA1}

Rats exposed to DDVP exhibited scattered degenerate and pyknotic neurons and reduced neuronal density in CA1 as shown in Figure 4B. Rats that received supplementation of VTE and VTC showed CA1 structure comparable with exposed groups as shown by few pyknotic cells and degenerate angulated neurons (Figure 5C and 5D). Rats that were treated with RPO supplementation showed fewer pyknotic cells and milder hypocellularity as compared with those that received VTE and VTC (Figure 5E).

\section{Histopathology of CA 3}

Rats exposed to DDVP showed patchy areas of neuronal loss, shrunken and degenerate angulated neurons in $\mathrm{CA} 3$ as displayed in Figure 6B. Rats that received supplementation of VTE and VTC showed reduction of cellular densities, few pyknotic cells and degenerate neurons as shown in Figures 7C and 7D. Rats that received RPO supplementation showed better preservation of CA3 neurons compared with the VTE and VTC as shown in Figure 7E which is comparable with the control of Figure 6A.

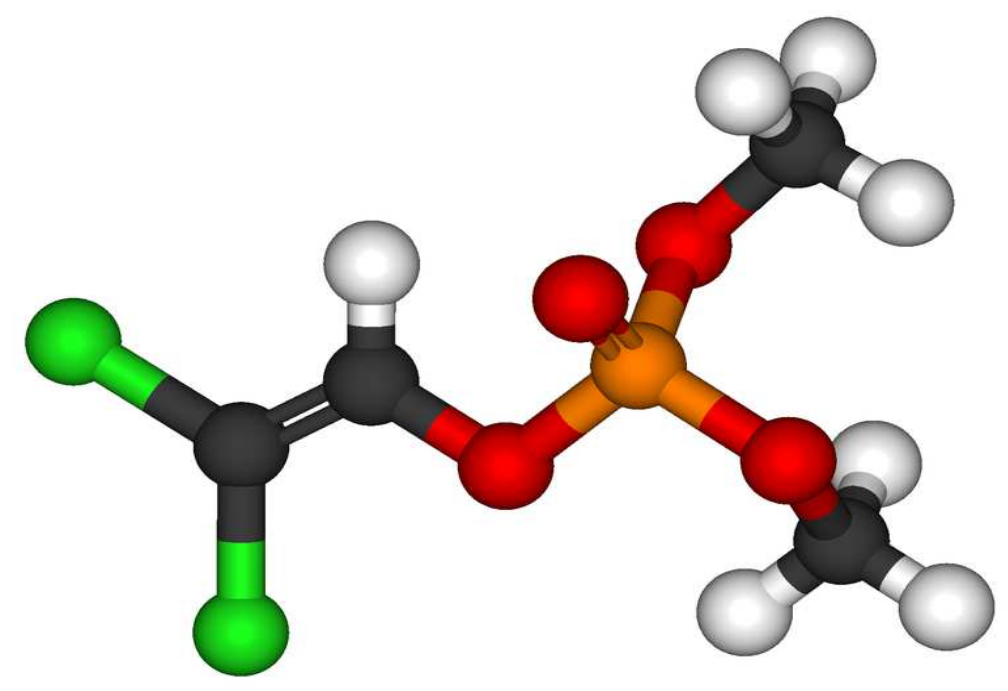

Figure 1: The ball-and-stick model of dichlorvos (O.-Odimethyl-O-2, 2-dichloro-vinyl phosphate) (USEPA, 2007). 

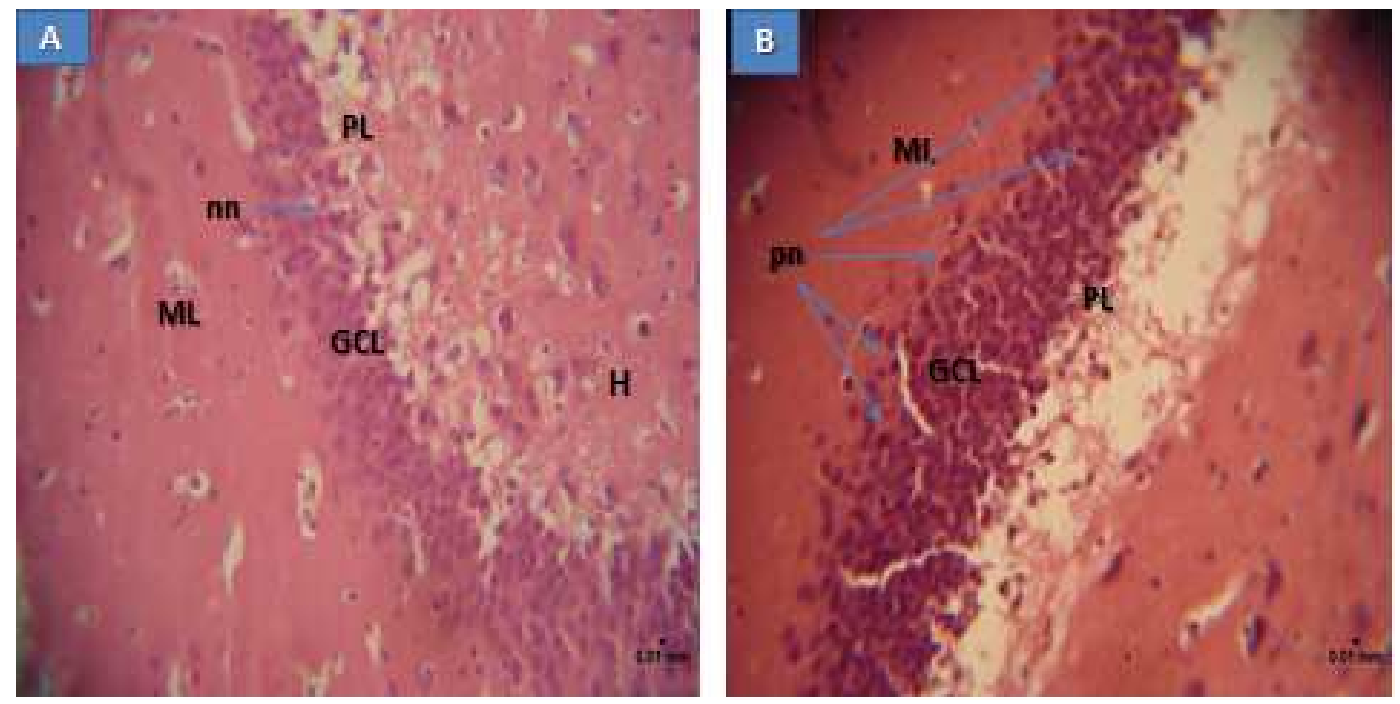

Figure 2: Representative photomicrographs of dentate gyrus of hippocampus of rats. A: control; B: DDVP exposure for 4 weeks; H \&E: stain; nn: normal neuron; pn: pyknotic neuron; ML: molecular layer; GL: granular layer; PL: polymorphic layer; H: hilus; Pyknotic granule cells are observed in B; Scale bars indicate $0.01 \mathrm{~mm}(10 \mu \mathrm{m})$.
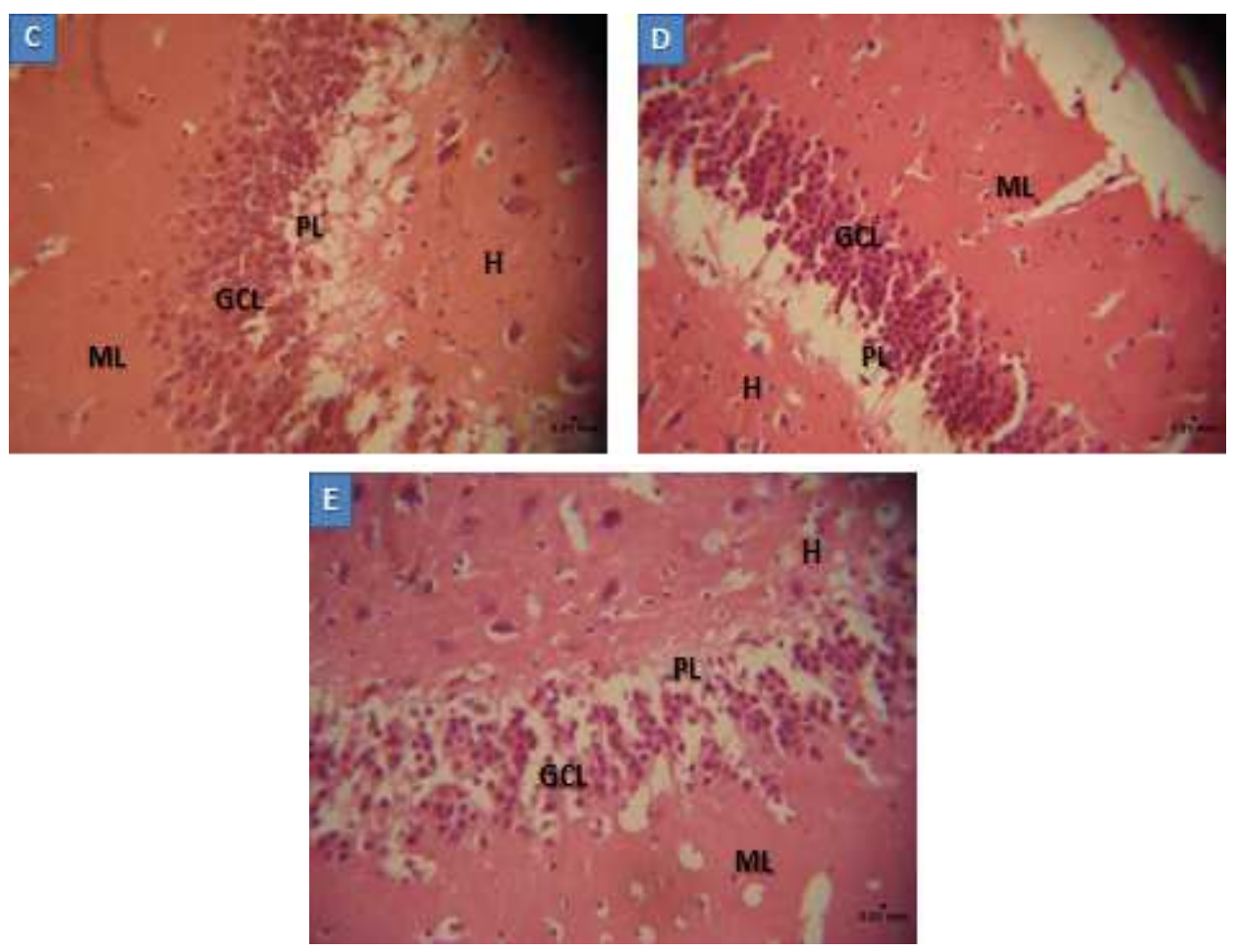

Figure 3: Representative photomicrographs of dentate gyrus of hippocampal formation of rats. C: DDVP+VTE; D: DDVP+VTC; E: DDVP + RPO; H \&E: stain; nn: normal neuron; pn: pyknotic neuron; ML: molecular layer; GL: granular layer; PL: polymorphic layer; H: hilus; VTE: vitamin E; VTC: vitamin C; RPO: red palm oil; Pyknotic neurons are not observed in A, B and C. Scale bars indicate $0.01 \mathrm{~mm}(10 \mu \mathrm{m})$. 

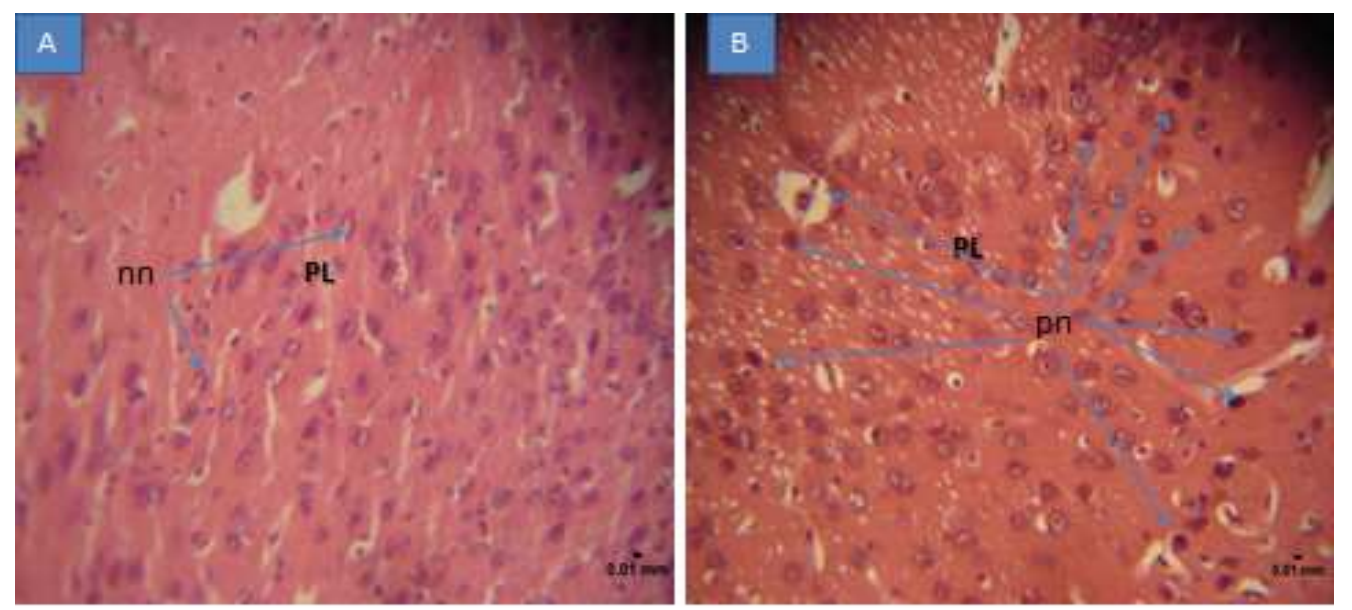

Figure 4: Representative photomicrographs of cornuammonis 1 field of hippocampus of rats. A: control; B: DDVP exposure for 4 weeks; H \&E: stain; nn: normal neuron; pn: pyknotic neuron; PL: pyramidal layer containing pyramidal neurons. Scaterred pyknotic pyramidal neurons are observed in B; Scale bars indicate $0.01 \mathrm{~mm}$ (10 $\mu \mathrm{m})$.
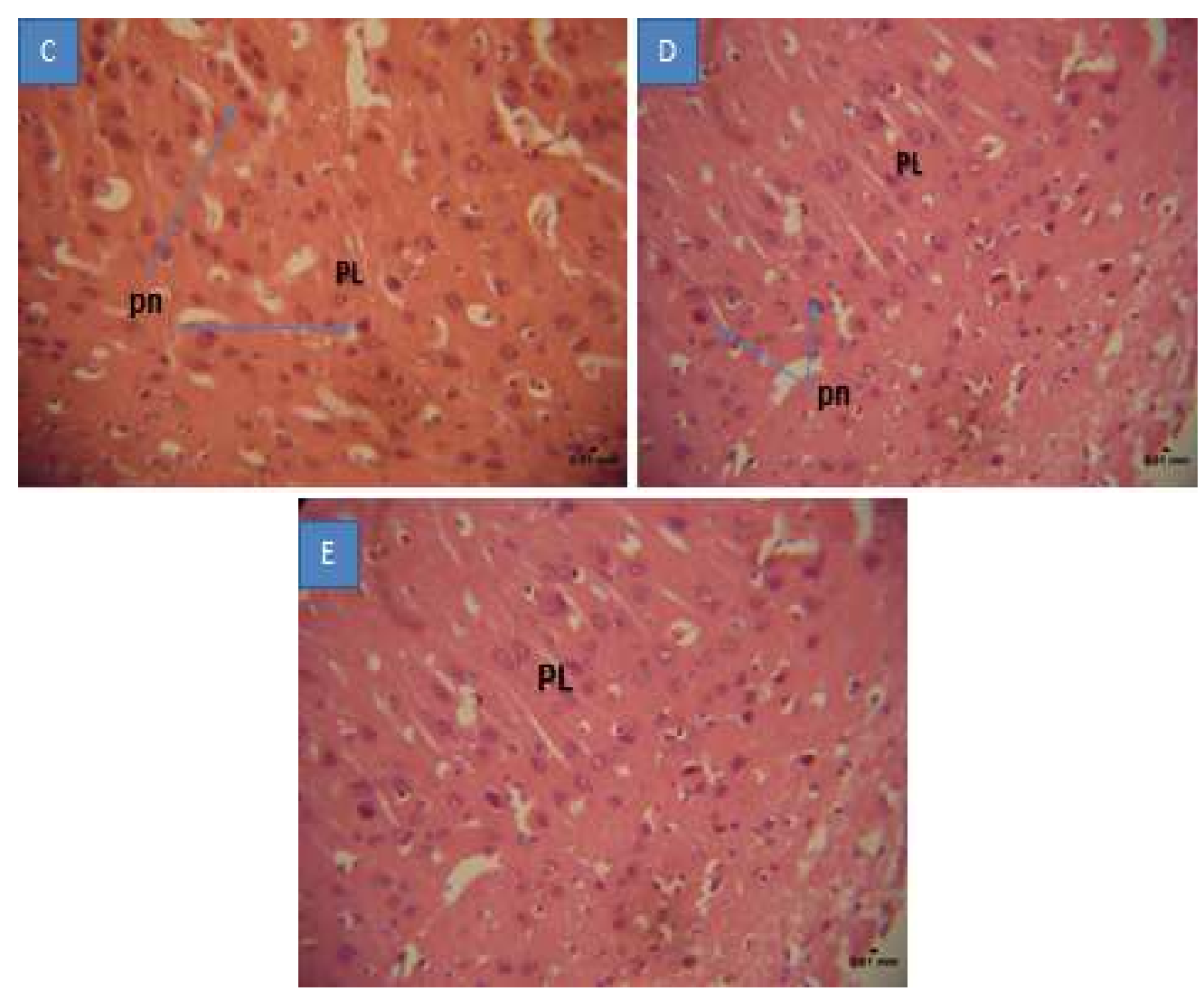

Figure 5: Representative photomicrographs of cornuammonis 1 field of hippocampus of rats. C: DDVP+VTE; D: DDVP+VTC; E: DDVP + RPO; H \&E: stain; nn: normal neuron; pn: pyknotic neuron; PL: polymorphic layer; H: hilus; VTE: vitamin E; VTC: vitamin C; RPO: red palm oil; Pyknotic pyramidal neurons scanty in C and D but absent in E. Scale bars indicate $0.01 \mathrm{~mm}(10 \mu \mathrm{m})$. 

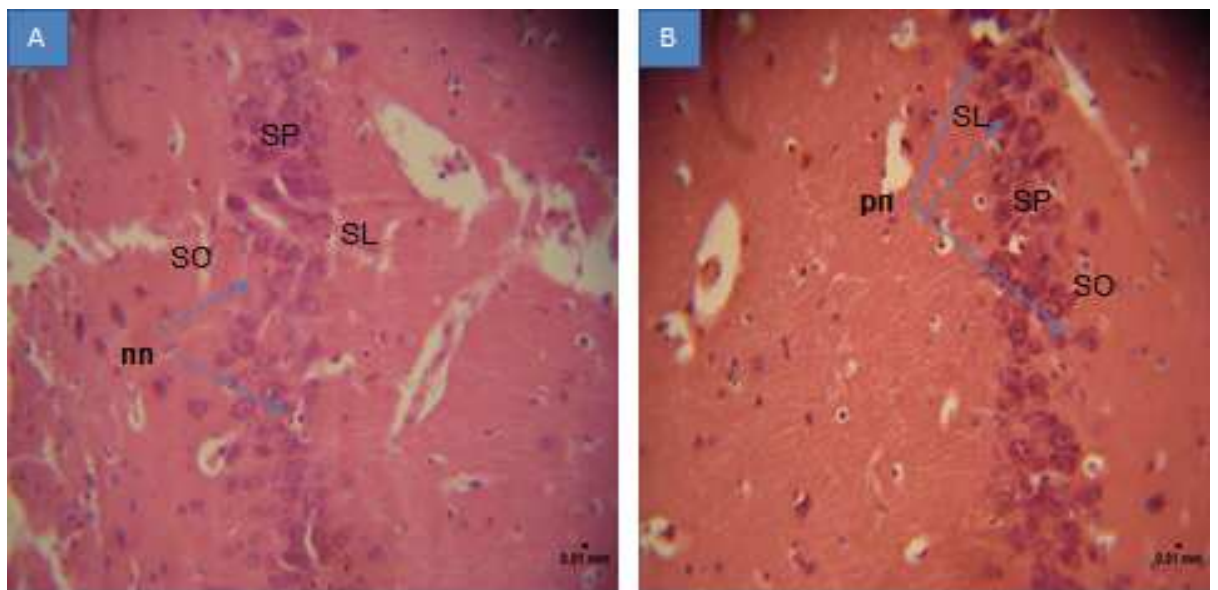

Figure 6: Representative photomicrographs of cornuammonis 3 field of hippocampus of rats. A: control; B: DDVP exposure for 4 weeks; H \&E: stain; nn: normal neuron; pn: pyknotic neuron; SO: stratum oriens; SP: stratum pyramidales; SL: stratum lucidum; Few scaterred pyknotic pyramidal neurons are observed in B; Scale bars indicate $0.01 \mathrm{~mm}(10 \mu \mathrm{m})$.
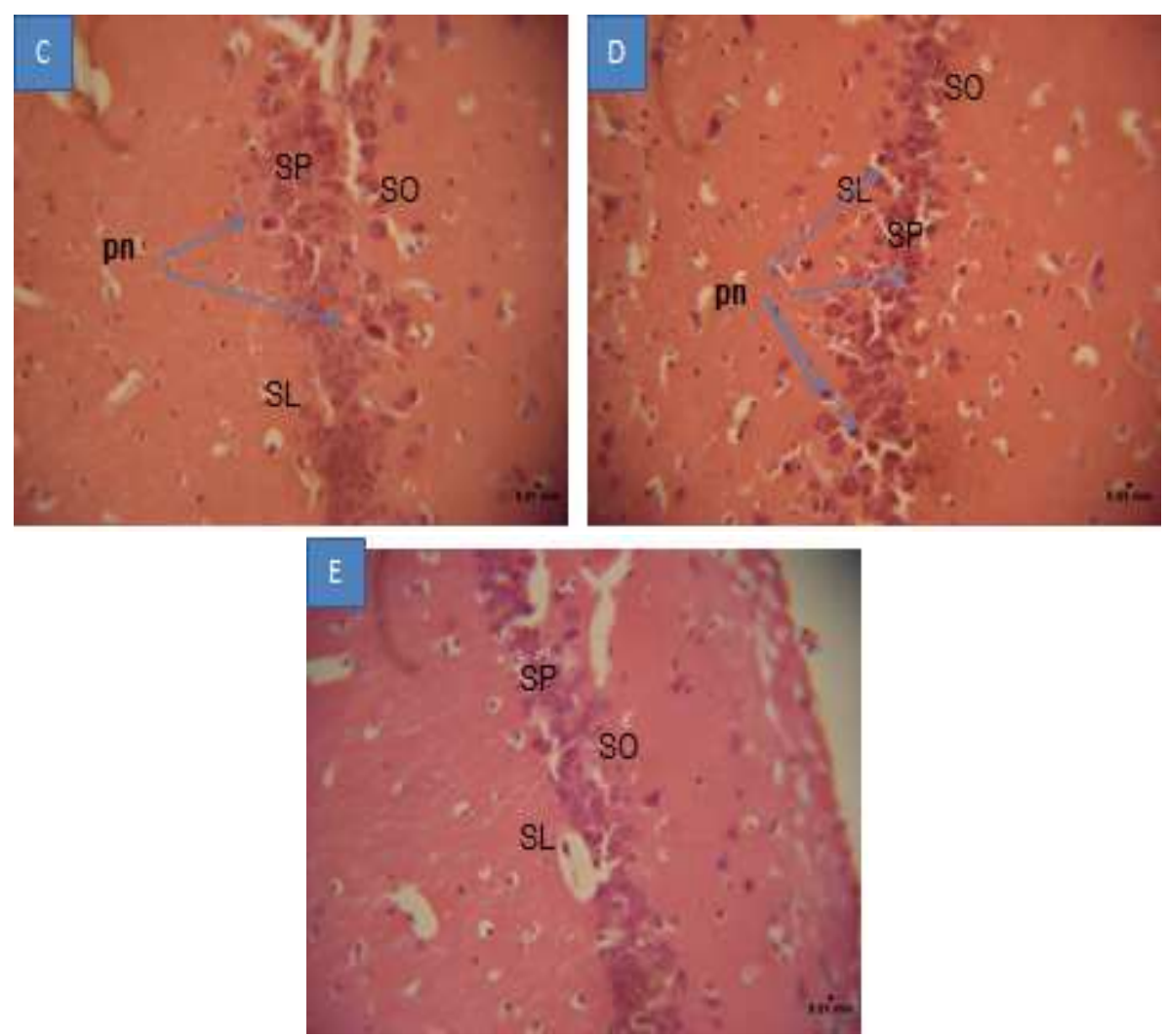

Figure 7 : Representative photomicrographs of cornuammonis 3 field of hippocampus of rats. D: DDVP+VTE; E: DDVP+VTC; F: DDVP + RPO; H \&E: stain; nn: normal neuron; pn: pyknotic neuron; SO: stratum oriens; SP: stratum pyramidales; SL: stratum lucidum; VTE: vitamin E; VTC: vitamin C; RPO: red palm oil; Pyknotic pyramidal neurons scanty in $\mathrm{C}$ and $\mathrm{D}$ but absent in $\mathrm{E}$. Scale bars indicate $0.01 \mathrm{~mm}(10 \mu \mathrm{m})$. 


\section{DISCUSSION}

This study has shown the neurotoxic effects of DDVP on the hippocampal formation of rats exposed to chronic inhalation of DDVP and the effects of vitamins on DDVP neurotoxicity. Reduced cellularity of the dentate gyrus, with neuronal degeneration and pyknosis of the dentate granule cell (DGC) nuclei is indicative of the toxicity of DDVP. Similar changes were seen in the pyramidal neurons of the CA1 and CA3 subfields, which is in agreement with the findings of Luty et al. (1998) who reported similar pyknosis in the pyramidal neurons of CA1 of rats treated dermally with DDVP. This suggests that DDVP exhibited its neurotoxicity irrespective of the route of administration since our rats were exposed to inhalational DDVP.

The neurotoxicity of DDVP may be due to oxidative damage induced by DDVP as described by Sharma and Singh (2012). Severe oxidative damage may lead to cell death by necrosis exemplified by the presence of nuclear pyknosis. The brain is considered more vulnerable to oxidative stress than any other organ of the body because it consumes high amount of oxygen, contains high content of polyunsaturated fatty acids (PUFA) and low level of antioxidant enzymes (Sharma and Singh, 2012).

The hippocampus proper and the dentate gyrus, as part of the hippocampal formation of the limbic system, play important roles in the acquisition of new memories, and are intimately involved in learning and spatial cognition (Somogyi, 2010; Vivar and van Praag, 2013) as well as in explicit long-term recognition memory (Shapiro and Eichenbaum, 1999; Olsen et al., 2012). They are also involved in cognitive functions especially in the areas of relational binding involving the association of disparate elements and comparison of externally presented information with stored/associated memory representations (Aloisi et al., 1997;
Olsen et al., 2012). Oxidative damage to the sub-ventricular zone of DG might affect the generation of new dentate granule cells (DGCs) as this would disturb the equilibrium of new neurons that should be added to the dentate gyrus (DG) of the adult mammalian brain (Piatti et al., 2013).

Pyknotic neurons indicate the onset of necrotic cell death (Stevens and Lowe, 2000) which is an indication of the toxicity of the chronic inhalation of DDVP, the implication of which is a potential reduction in the functional efficiency of the classical intrinsic hippocampal circuit neuronal pathways associated with these neural structures. In this circuit, information is considered to be processed from entorhinal cortex (EC) to DG, DG to CA3 pyramidal cells, and from CA3 to CA1 pyramidal cells to be ultimately stored in cerebral cortex (Amaral and Witter, 1989; Nakazawa et al., 2004). Functionally, neural information relays from the entorhinal cortex via two major cortical inputs, the medial entorhinal cortex (MEC) and lateral entorhinal cortex (LEC) (Johnston and Amaral, 1998; Van Cauter et al., 2012). This comes in via the perforant path to the molecular layer of DG and may be affected when there is neuronal death in terms of impulse transmission and relay (Ming and Song, 2011). DGCs are the principal neurons of the DG, which constitute the main gateway to the hippocampus (Piatti et al., 2013). Granule cell death might affect the passage of neural information coming in to the molecular layer of DG. The second part of this circuit arises from the projection cells of the dentate gyrus, the granule cells, which send their axons to the pyramidal cells of CA3 (Ribak and Shapiro, 2007. Neuronal death would no doubt affect the axons of DGCs (mossy fibres) arising from the granular layer of DG as they proceed on the way to CA3 (Jaffe and Gutiérrez, 2007). It is from CA3 that Schaffer's collaterals will project on to the CA1 neurons, and finally to the subiculum, en route to entorhinal cortex, 
though CA3 may project back directly to the DG (Scharfman, 2007). Neuronal death along the pathway reduces the effectiveness of the neural information which may lead to a reduction in the function of the hippocampal formation in its memory encoding and longterm recognition memory capabilities.

Since ROS generation is the reported basis for the oxidative damage of DDVP (Sharma and Singh, 2012), the use of exogenous antioxidants should be able to neutralize the effects of ROS. As an electron donor, VTC donates an electron to free radicals to neutralize them as has been reported (Padayatty et al., 2003). Vitamin E (VTE) is an intracellular compound associated with lipid-rich biological membranes of which neuronal membranes made up of multilayers of lipid is a good example. Such membranes are subject to lipid peroxidation when exposed to the DDVP toxicity, but because of its lipophilic nature, VTE as a major free radical chain terminator might have terminated such peroxidative reaction (Singh, 2002). The combination of VTE in red palm oil in addition to beta-carotene and other type of carotenes enhances its anti-oxidative potentials, hence the amelioration observed in the granule cells of the brain of red palm oiltreated rats in our study. However, unlike the case with the fascia dentata where VTC and VTE effectively ameliorated the effect of DDVP-induced toxicity, both multivitamins did this partially in the CA1 and CA3 subfields of the hippocampus proper. Red palm oil, however, was able to reduce the effect of DDVP on the pyramidal neurons; this effect is most probably due to the combination of VTE in red palm oil in addition to vitamin $\mathrm{A}$ in form of beta-carotene and other type of carotenes (Bonnie and Choo, 2000). This must have increased the potency of the anti-oxidative activity of red palm oil helping it to ameliorate the neurotoxic effect of DDVP in the brain of red palm oil-treated rats.
Taken together, our findings imply that chronic inhalation of DDVP may adversely affect the memory component of cognition and that antioxidants as present in RPO may reduce this effect. It may also be inferred that patients suffering from degenerative neurological disorders like Alzheimer's disease should be prevented from undue exposure to pesticides containing DDVP since the basic pathology of their ailment is in the hippocampus and chemical injury of the hippocampal formation might tend to worsen such conditions. Younger healthy individuals should also be encouraged to take precautionary measures to avoid hippocampal injury due to undue and prolonged exposure to prevent impairment of learning and memory.

\section{Conclusion}

Inhalational DDVP caused toxic changes in the dentate granule neurons and pyramidal neurons of CA1 and CA3 of the hippocampus which were ameliorated by red palm oil and partially by vitamins $\mathrm{E}$ and $\mathrm{C}$.

\section{ACKNOWLEDGMENTS}

We thank Mr. C. I. Iheakanwa of the Department of Veterinary Anatomy, University of Ibadan for help with preparation of the histological slides.

The authors declare that the research was conducted in the absence of any commercial or financial relationships that could be construed as a potential conflict of interest.

\section{REFERENCES}

Akinyoola SB, Edem VF, Arinola OG, Owoeye O. 2012. Vitamin E or red palm oil increases the level of nitric oxide in Wistar rats exposed to dichlorvos. Trop. J. Health Sci., 2: 1-11.

Aloisi AM, Zimmermann M, Herdegen T. 1997. Sex-dependent effects of formalin and restraint on c-Fos expression in the 
septum and hippocampus of the rat. Neuroscience, 81: 951-958.

Amaral DG, Witter MP. 1989. The threedimensional organization of the hippocampal formation: a review of anatomical data. Neuroscience, 31: 571591.

Ambali SF, Ayo JO, Ojo SA, Esievo KA. 2011. Ameliorative effects of vitamin $C$ on chronic chlorpyrifos-induced erythrocyte osmotic fragility in Wistar rats. Human Experimental Toxicology, 30(1): 19-24.

Arinola OG, Akinosun OM, Olaniyi JA. 2011. Passive and active cigarette smoking: effects on the levels of antioxidant vitamins, immunoglobulin classes and acute phase reactants. Afr. J. Biotech., 10: 6130-6132.

Bancroft JD, Gamble M. 2008. Theory and Practice of Histology Techniques $\left(6^{\text {th }}\right.$ edn). Churchill-Livingstone Elsevier: Philadelphia; 121-134.

Bonnie TYP, Choo YM. 2000. Valuable minor constituents of red palm olein: carotenoids, vitamin E, ubiquinones and sterols. J. Oil Palm Res., 12(1): 14-21.

DesiI, Nagymajtenyi L. 1998. Neurotoxicologic investigations of the pesticide dichlorvos (DDVP). Effects on the central and peripheral nervous system. Toxicol., 49: 141-148.

Edem VF, Akinyoola SB, Olaniyi JA, Rahaman SK, Owoeye SK, Arinola OG. 2012. Haematological parameters of Wistar rats exposed to 2, 2 dichlorovinyl dimethyl phosphate chemical. Asian $J$. Exp. Biol. Sci., 3(4): 1-4.

Hagar HH, Fahmy AH. 2002. A biochemical, histochemical, and ultrastructural evaluation of the effect of dimethoate intoxication on rat pancreas. Toxicol. Lett., 133: 161-170.

Hazarika A, Sarkar SN, Hajare S, Kataria M, Malik JK. 2003. Influence of malathione pretreatment on the toxicity of anilofos in male rats: A biochemical interaction study. Toxicology, 185: 1-8.

Hendelman WJ. 2000. Atlas of Functional Neuroanatomy. CRC Press LLC: Boca Raton; 187-199.

Jaffe DB, Gutiérrez R. 2007. Mossy fiber synaptic transmission: communication from the dentate gyrus to area CA3. Prog Brain Res, 163: 109-132.

Johnston D, Amaral DG. 1998. Hippocampus. In The Synaptic Organization of the Brain. (4 $4^{\text {th }}$ edn), Shepherd GM (ed). Oxford University Press: New York; 417458.

Joshi SC, Mathur R, Gajraj A, Sharma T. 2003. Influence of methyl parathion on reproductive parameters in male rats. Environ Toxicol. Pharmacol, 14: 91-98.

Kesner RP. 2007. Behavioral functions of the CA3 sub-region of the hippocampus. Learn. Mem., 14: 771-781.

Luty S, Latuszynska J, Hanina H, Tochman A, Obuchowska D, Przylepa E, Korczak E, Bychawski E. 1998. Toxicity of dermally absorbed dichlorvos in rats. Ann. Agric. Environ Med., 5: 57-64.

Ming GL, Song H. 2005. Adult neurogenesis in the mammalian central nervous system. Annu. Rev. Neurosci., 28: 223-250.

Murthy VK, Shipp JC, Hanson C, Shipp DM. 1992. Delayed onset and decreased incidence of diabetes in BB rats fed free radical scavengers. Diabetes Research and Clinical Practice, 18: 11-16.

Musa U, Hati SS, Mustapha A, Magaji G. 2010.Dichlorvos concentrations in locally formulated pesticide (Ota piapia) utilized in northeastern Nigeria. Sci. Res. Essay, 5: 49-54.

Nakazawa K, McHugh TJ, Wilson MA, Tonegawa S. 2004. NMDA receptors, place cells and hippocampal spatial memory. Nat Rev Neurosci., 5(5): 361372.

Neishabouri EZ, Hassan ZM, Azizi E, Ostad SN. 2004. Evaluation of immunotoxicity 
induced by diazinon in $\mathrm{C} 57 \mathrm{bl} / 6$ mice. Toxicology, 196: 173-179.

Olsen RK, Moses SN, Riggs L, Ryan JD. 2012. The hippocampus supports multiple cognitive processes through relational binding and comparison. Front Hum. Neurosci., 146: 1-12.

Owoeye O, Edem FB, Akinyoola BS, Rahaman S, Akang EEU, Arinola OG. 2012. Histological changes in liver and lungs of rats exposed to dichlorvos before and after vitamin supplementation. Eur. $J$. Anat., 16(3): 190-198.

Padayatty SJ, Katz A, Wang Y, Eck P, Kwon O, Lee JH, Chen S, Corpe C, Dutta A, Dutta SK, Levine M. 2003. Vitamin C as an antioxidant: evaluation of its role in disease prevention. J. Am. Coll. Nutr., 22(1): 18-35.

Piatti VC, Ewell LA, Leutgeb JK. 2013. Neurogenesis in the dentate gyrus: carrying the message or dictating the tone. Front Neurosci., 7: 50. doi: 10.3389/fnins.2013.00050

Public Health Service (PHS). 1996. Public Health Service Policy on Humane Care and Use of Laboratory Animals. US Department of Health and Human Services: Washington, DC; 99-158.

Ribak CE, Shapiro LA. 2007. Ultrastructure and synaptic connectivity of cell types in the adult rat dentate gyrus. Prog Brain Res, 163: 155-166.

Scharfman HE. 2007. The CA3 "backprojection" to the dentate gyrus. Prog Brain Res, 163: 627-637.

Schneider CA, Rasband WS, Eliceiri KW. 2012. NIH Image to Image J: 25 years of image analysis. Nat Methods, 9(7): 671675.

Shapiro ML, Eichenbaum H. 1999. Hippocampus as a memory map: synaptic plasticity and memory encoding by hippocampal neurons. Hippocampus, 9: 365-384.

Sharma P, Singh R. 2012. Dichlorvos and lindane induced oxidative stress in rat brain: protective effects of ginger. Pharmacognosy Res., 4(1): 27-32.

Singh SP. 2002. A Textbook of Biochemistry, ( $3^{\text {rd }}$ edn). CSB Publishers: New Delhi; 545-555.

Somogyi P. 2010. Hippocampus: intrinsic organisation. In Hand of Brain Microcircuits, Shepherd P, Grillner S (eds). Oxford University Press: New York; 148-164.

Stevens A, Lowe J. 2000. Pathology $\left(2^{\text {nd }} e d n\right)$. Mosby Harcourt Publishers Limited: Edinburgh; 23-33.

Tranel D. 1995. Higher brain functions. In Neuroscience in Medicine, Conn PM (ed). JB Lippincott Company: Philadelphia; 555-580.

USEPA. 2007. Dichlorvos TEACH chemical summary US EPA: Toxicity and exposure assessment for children. http://www. epa.gov/teach/, 1-13.

VanCauter T, Camon J, Alvernhe A, Elduayen C, Sargolini, F, Save E. 2013. Distinct roles of medial and lateral entorhinal cortex in spatial cognition. Cereb Cortex, 23: 451-459.

Verma RS, Srivastva N. 2003. Effect of chlorpyrifos on thiobarbituric acid reactive substances scavenging enzyme and glutathione in rat tissues. Indian $J$. Biochem. Biophysics, 40: 423-428.

Vivar C, VanPraag H. 2013. Functional circuits of new neurons in the dentate gyrus. Front. Neural Circuits, 7: 15.doi: 10.3389/fncir. 2013.00015.

Wyss JM, Groen TV. 1995. The Limbic system. In Neuroscience in Medicine, Conn PM (ed). JB Lippincott Company: Philadelphia; 321-342. 